\title{
QUAD system offers fair shares to all authors
}

\section{Showing who did what could solve the problem of authorship abuse and disputes.}

Sir - Authorship is the currency of modern science, the measure of one's contribution to the literature. Yet while the contents of an article are held to strict scientific standards, the recognition of authorship is far less so.

With no accepted system to guide the process by which authors are recognized for their individual contributions, and with the numbers of authors per article steadily increasing, the incidence of authorship disputes and abuse is rising, as Eugen Tarnow noted in Correspondence ("When extra authors get in on the act" Nature 398, 657; 1999).

Certain medical journals now require authorship declarations, although these are always qualitative. We suggest a quantitative method for evaluating authorship based on four categories of contribution: conception and design, data collection, data analysis and conclusions, and manuscript preparation. Each author would claim their percentage share of the total credit in each of the four categories. The least that one could contribute to a paper would be $10 \%$ within a single category, placing a theoretical limit of 40 on the total number of authors.

Authors would usually be listed in descending order of total contribution across all four categories. When equal sums are reported, the listing could be made alphabetically, and for large collaborations, either groups or individuals may declare their contributions. Journals would be free to choose their own categories, but these would ideally be uniform across all papers.

The percentage share could be indicated as in the following example, reflecting a typical distribution in a studentmentor relationship in which the student, $\mathrm{S}$, is responsible for $20 \%$ of conception and design, $90 \%$ of data collection, $80 \%$ of data analysis and conclusions and $20 \%$ of manuscript preparation: $\mathrm{S}^{20,90,80,20}, \mathrm{M}^{80,10,20,80}$.

The explicit nature of this system, dubbed Quantitative Uniform Authorship Declaration (QUAD), permits the reader to identify who contributed what, rapidly and easily. It should also discourage distortions of authorship by co-authors in positions of power and help reduce the numbers of honorary authorships.

Without external monitoring, it would be impossible to guarantee that all the authors have described their contributions accurately. However, the quantitative and transparent nature of QUAD should help reduce such behaviour.

Journals that have introduced authorship declarations have seen only partial adoption by authors, but we hope that many more journals and authors will welcome the advantages offered by QUAD. Ultimately, this system will prove more useful than existing ad hoc methods when scientists and administrators are faced with funding and hiring decisions.

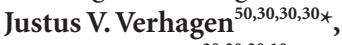

Karin J. Wallace $30,30,30,10 \dagger$,

Stephan C. Collins $\mathrm{s}^{20,40,20,10} \neq$,

Thomas R. Scott ${ }^{0,0,20,50} \$$

${ }^{*}$ Department of Experimental Psychology,

University of Oxford, South Parks Road,

Oxford OX1 3UD, UK

$\dagger$ Wellcome Trust Centre for Human Genetics,

University of Oxford, Roosevelt Drive,

Oxford OX3 7BN, UK

\$The Wellcome Trust Sanger Institute,

Hinxton, Cambridge CB10 1SA, UK

$\$$ College of Sciences, San Diego State University,

5500 Campanile Drive, San Diego,

California 92182-1010, USA

Nature's authorship policy is that authors are strongly encouraged to include a statement in the Acknowledgements to specify the actual contribution of each co-author. See www.nature.com/nature/ submit/policies/index.html\#2 - Editor, Correspondence

\section{Tidewater glaciers move at their own pace}

Sir-Arctic warming is receiving much scientific scrutiny and public interest, and your News Feature about Alaska's climate

"Too hot to handle" (Nature 425, 338-339; 2003) gives a generally accurate overview of the reasons why the Arctic deserves our continued attention. However, one ongoing event in your list of direct consequences of recent Arctic warming, the rapid retreat of Columbia Glacier, should not be there.

Columbia Glacier is one of many tidewater glaciers - glaciers that terminate in the ocean but do not float - that fringe Alaska's central and southern coasts. They are well-known to advance and retreat out of synchrony with landterminating glaciers, and even with each other. Climate appears to control tidewater glacier advance and retreat only on long (millennial) timescales; shorter annual, decadal, and even century-to-century comparisons do not show a close relationship between tidewater glacier activity and climate.
Early European explorations of Alaska at the end of the eighteenth century showed that tidewater glaciers in southern Alaska were fully extended, with termini reaching all the way to the coast, but during the nineteenth and early twentieth centuries these glaciers rapidly retreated, exposing such long and deep fjords as Johns Hopkins Inlet and Disenchantment Bay. Columbia Glacier attained its advanced position between the fifteenth and nineteenth centuries, and only since the early 1980s has it started its retreat.

The end of Columbia Glacier has retreated roughly 13 kilometres from its pre-1980 position, and continues to retreat at roughly half a kilometre per year while discharging some 11 cubic kilometres of ice per year into Prince William Sound. But as Columbia Glacier retreats, Hubbard Glacier, 400 kilometres to the southeast in Disenchantment Bay, has been advancing since 1980 .

None of this is to say that tidewater glacier behaviour is irrelevant to presentday concerns about climate change. Tidewater glaciers are affected by climate change on long timescales (primarily through accumulation of mass by snowfall and loss by melt), but are even more strongly affected on short timescales by the ocean, through the influence of heat advection and forces of hydrostatic water pressure. These factors add great complexity to tidewater glacier dynamics and result in nonlinear and irreversible responses to climate, which on long timescales does indeed control all glacier growth and contraction.

Arctic warming is very real, but the complicated interaction between tidewater glaciers, oceans and climate and the likelihood that tidewater glacier retreat may not be caused directly by the current climate - should be more widely recognized.

\section{W. T. Pfeffer}

Department of Civil, Environmental and Architectural Engineering and Institute of Arctic and Alpine Research, Campus Box 450, University of Colorado, Boulder, Colorado 80309-0450, USA

\section{correspondence}

Contributions to Correspondence may be submitted to corres@nature.com. They should be no longer than 500 words, and ideally shorter. Published contributions are edited. 